\title{
Eusebio de Cesarea y la historia de la Iglesia. Para una historia de la Iglesia a partir de los pobres
}

\section{EDUARDO HOORNAERT \\ Profesor del Instiluto de Ciencias Religiosas Fortaleza, Brasil.}

\section{Cristianismo e historia}

En contraste con otras religiones, el judaísmo y el cristianismo son por excelencia religiones de "memoria," fundamentadas en la memoria de hechos históricos que quedan graba. dos a lo largo de los tiempos. El éxo. do posibilitó la formación de una me. moria colectiva en el puebio judio que no encuentra paralelo en otros pueblos y de una religión basada en esta memoria.

Para los israelitas la historia no era cíclica, basada en un eterno retorno de las cosas y de los tiempos, sino que tenía una finalidad y era, por con. siguiente, irreversible. Los judios fueron los primeros en la historia de la humanidad en concebir la historia co. mo dirigida hacia un lill. Esa concep. ción judia contrastaba vivamente con el pensamiento griego que era esencialmente anti-histórico y basado en el "eterno retorno de situaciones iguales," de suerte que para los griegos nada realmente nuevo acontecía bajo el sol: nihil novi sub sole. La filosofia griega se dirigía preferentemente hacia lo eterno e inmu- table. Cuando los griegos, como Herodoto o Tucídides, se interesaban por la historia, era para sacar de ella sus lecciones políticas. Podemos, por consiguiente, calificar la historiografía griega de pragmática; no tocaba lo întimo de la existencia humana, no tenía una dimensión religiosa.

El cristianismo heredó del judaísmo su carăcter memorativo, sólo que centró su memoria en la encarnación, vida, pasiōn, muerte y re. surrección de Cristo Jesús, el liberador no sólo de Egipto - como lo fuera Moisés - sino de todas las formas de dominación. En contraste con el judaísmo, en el seno del cual nació, e! cristianismo coloca el centro de la his. toria en Cristo y en el reino por él iniclado. Los judíos continúan esperan. do el mesias mientras los cristianos ya realizan en el tiempo y en el espacio el reino iniciado por Jesús. La mirada de los cristianos está fija en Cristo, lo cual explica por qué el tema de la es. peranza está vinculado al tema de la memoria: la memoria sostiene la espe. ranza y sin memoria cristiana se des. vanece la esperanza. De aquí se deduce para los cristianos la necesidad 
del recuerdo como tarea religiosa fundamental, como se comprueba en que la enseñanza cristiana es a fin de cuentas 'memorización' y en que la liturgia cristiana es 'rememoración.'

Por todo esto no se puede olvidar el carácter peculiar de la memoria cristiana. Ella fue y continúa siendo frecuentemente una memoria de vencidos y humillados, marginados y despreciados. Como tal, no se articula con facilidad en una "historia," escrita según la tradición hegemónica de la historiografia en las grandes culturas, a través de discursos, monumentos, archivos, iconografia, arquitectura, a no ser que se haga una lectura metódicamente correcta de estas fuentes. Aquélla, por el contrario, se transmite de generación en generación como una cultura popular, una tradiciōn oral, una resistencia cultural. Por ello la memoria cristiana sobrevive sobre todo en comunidades. Existe una intima relación entre memoria cris. tiana y comunidad de base. La advertencia de San Pablo, la palabra de Dios no puede quedar encadenada, presupone la búsqueda por parte de los cristianos de instrumentos institucionales que puedan garantizar la libertad de la palabra de Dios frente a las presiones y manipulaciones de parte de los poderes de este mundo.

Es responsabilidad fundamental de la práctica cristiana buscar mode. los sociológicos de Iglesias que garanticen la libertad de la palabra de Dios. Los cristianos no pueden ser indiferentes ante esto, pues recibieron la sagrada misión de "hacer esto (la celebración eucarística) en memoria mía" (Lc. 22, 19), de guardar a través de los tiempos la memoria de Jesús, de los apostóles, de los profetas y de toda la historia de la alianza de Dios con los hombres.

En esta perspectiva se inserta la tarea de la historia de la Iglesia. En una bella expresión, el historiador francés H. 1. Marrou define el historiador como "un misionero enviado al pasado para establecer la línea de uniōn entre este pasado y el presente. "La historia de la Iglesia cumple su papel en la mi. sión de reavivar entre las comunida. des la memoria auténtica de Jesús y del reino. El historiador eclesiástico tiene que responder a las preguntas vivas que el pueblo cristiano hace a partir de la experiencia comunitaria. También en los comienzos los cris. tianos se reunieron para resolver sus problemas: los primeros cristianos, ¿eran ricos o pobres? ¿Estaban ya animados por la misma esperanza que hoy nos hace caminar? ¿Cuál era su relación con los poderosos y con la politica?

La historia de la iglesia es una ciencia al servicio de la memoria co. lectiva del pueblo cristiano reunido en comunidad. La misión del historiador cristiano se sitúa frente al pedido de auxilio que surge de las comunidades. Lo que J. Le Goff afirma sobre el historiador en general vale también para el cristiano, "la tarea del historiador es la de transformar la memoria en ciencia. "La tarea no con. siste sólo en captar la memoria de las comunidades, sino también en transformarla en discurso coherente, basado en documentos objetivos, confirmado por la investigación seria $y$ científica. Para llegar a tal objetivo tenemos que evitar tanto el populis. mo como el totalitarismo historiográfi. co. El pueblo, por un lado, tiene derecho a la historia en su sentido pleno y no sólo a episodios edificantes, intermitentes e incompletos; debe sa- 
ber descubrir las causas y los motivos de los acontecımientö. En nada ayuda a una historia de la Iglesıa al servi. cio de las comunidades nuevas leyendas, nuevas apologéticas, nuevos triunfalismos, renovados populismos. No se deben estudiar sólo los aspec tos triunfales del pasado, sino tam bién y sobre todo las luchas, los peca. dos, las falsas alianzas que el cris. tıanısmo hıstórıco cometió por intere. ses no siempre evangélicos. Por otro lado, una historia de la Iglesıa al servi. $\mathrm{clo}$ de la memoria colectiva del pueblo cristiano debe evitar también los peligros del historicismo totalitario provocado por las desviaciones de una interpretación marxista dema. siado dogmática, mecanicista $y$, al final de cuentas, inhumana, segün la cual todo tendria que recomenzar a partir del punto cero. La tradición eclesiástica nada tendría de bueno ni de constructivo, la Iglesia siempre habría estado en el lado equivocado y la función del clero siempre habría sido la de domesticar y controlar al pueblo. Generalizaciones como éstas no ayudan en nada ciertamente a la construcción de la memoria de las comunidades, pues en el fondo proce. den de un anti-intelectualismo que rechaza todo y cualquier esfuerzo por penetrar en puntos complejos co. mo son los históricos.

\section{Eusebio de Cesarea y la historla de la Iglesla}

$\mathrm{El}$ intento de elaborar un discurso historiográfico que pueda dar base científica a la memoria del pueblo cristiano se enfrenta inevitablemente con una larga tradiciön que se remonta a un escritor eclesiástico del siglo cuarto, Eusebio de Cesarea (263339). ${ }^{\top}$ Eusebio, obispo de Cesarea en
Palestina, escribió una Historia eclesiástica en diez libros en un momento de grandes cambios para la Iglesia. Su modo de escribir contrastaba con el de escritores eclesiästicos anteriores por la fidelidad con que transcribía los documentos de la Iglesia antigua, especia!mente de Asia Menor, Sirla y Egipto, mientras que los anteriores mezclaban historia y leyenda, narración y exhortaciōn. Habiendo frecuentado la famosa escuela fundada por Orígenes (185.253) en Cesarea, fue muy estimado por el propio emperador Constantino por su erudicción, siendo designado por el propio emperador para pronunciar el discurso oficial conmemorando los 30 años de su gobierno y la glorificación de la nueva ciudad de Constantinopla. La escuela de Cesarea poseía una biblioteca estimada en 30 mil volúmenes, la cual fue llamada por Adolfo von Harnack, el gran estudioso de la helenización del cristianismo, "la biblioteca-madre de las bibliotecas medievales." La escuela con biblioteca constituyó el centro de formación măs importante de la Iglesia en los siglos III y IV, de modo que la autoridad de Eusebio fue reconocida en toda la Iglesia. Esto significa la transición definitiva de la tradición oral para mantener la memoria cristiana a la tradiciōn escrita, segura y definitiva.

La Historla ecleslástlca dedica 7 de sus 10 libros a los acontecimientos anteriores a la gran persecuciōn de Diocleciano, la cual comenzó en 284. Esta fecha quedó grabada con tanta fuerza en la memoria de los cristianos que éstos computaron el tiempo y los años a partir de ella. El cómputo a partir del nacimiento de Jesús sólo se impuso más tarde, en el siglo IX. Los 3 primeros libros de Eusebio tratan de 
Jesús, de los apóstoles y de la edad postapostólica. Los libros 4, 5, 6 y 7 ofrecen básicamente cuatro puntos: las listas episcopales de las iglesias de Jerusalén, Roma, Antioquía y Alejandria, las grandes herejias, los principales escritores eclesiáslicos y la persecuciön por parte de judios y paganos Los libros 8 y 9 tratan de la "persecu. ción de nuestros dias," cuya memoria estaba viva en la mente de los lectores, mientras el libro 10 cuenta la "vic. toria" bajo Constantino y la historia de los mártires de Palestina, así como la vida de Constantino.

Esta simple enumeración permite ya captar que el punto de apoyo en torno al cual se articula la obra de Eusebio es el de la dicotomia "per. secución-victoria," "opresión. libertad," "ortodoxia-herejia;" y hay que reconocer que a él se debe predominantemente la imagen que el cristianismo histórico arrastra consigo a través de los siglos sobre la "era de las persecuciones" en contraste con los "tiempos cristianos" (christiana tempora). Volveremos sobre este punto tan importante, pero antes hay que recordar los méritos de Eusebio en la historiografía cristiana, tan evidentes que nadie los cuestiona: superó con maestría la postura historiográfica cristiana anterior y comenzó a afrontar seriamente las estructuras propias de la historia y de la "larga duraciōn" de ésta; rompió con la función histōrica del "destino" (fatum, hecho) - tan tipica de la historiografía griega- substituyéndolo por la racionalidad de la providencia, o sea, de la razón divina que gobierna el mundo; expresó también el humanismo cristiano, atento y sensible a lo pequeño y despreciado a los ojos del mundo (véase en este sentido la admi- rable página acerca de Elandına, már. tir cristiana: Hist. Ecl., 5, 1, 17). A un nivel de técnica historıográfica, Eusebio fue el primer historlador cristiano que citó fielmente el material usado, identificando correctamente las fuen tes. Su obra maestra paciencia, escrú. pulo y excelente organización del material. Para diversos campos de nuestro conocimiento de los tres pri. meros siglos del cristianısmo depen. demos enteramente de las informa. ciones dadas por Eusebro, asi como para el conocimiento del famoso "cristianismo rabinico," también lla. mado "Iglesia de la circuncisión," de Hegésipo en particular, de la ida de San Pedro a Roma -únicamente citada por Eusebio en su Hist. Ecl. $2,14,6,{ }^{3}$ del montanismo 4 . o incluso de la cuestión pascual al final del siglo II cuya documentación Eusebio investiga exhaustivamente.

Pero todo esto no quita que Eusebio no tenga ya una tesis al escribir su historia; y esa tesis aparece con claridad en la dicotomia que establece con tanta nitidez entre la victoria de la Iglesia con Constantino y sus dificultades antes de este emperador. La imagen que presenta de las persecuciones es altamente simbólica, basada en una comparación con las diez pla. gas de Egipto. Así como hubo diez plagas, asi tambiēn hubo diez persecuciones. Constantino es presentado como liberador, una especie de Moisés. La Historia ecleslástica muestra una determinada visión de la Iglesia inspirada en un apasionado entusiasmo por el "líder" Constantino." Se puede presumir que esta visiōn representa a un sector de los dirigentes cristianos de la época, el sector que quedó entusiasmado por las nuevas relaciones políticas creadas a 
la sombra de Constantino, que las proyecta al nivel del plan divino, hace una leologia imperial o una teología de la historia totalmente nueva ade. cuada a la época. Pero es dificil imagiriar que iodos los sectores cristianos de la época estuviesen de acuerdo con esta visión to que ccurre es que Eusebio, con su esfuerzo historiogräfi. co, consıguió crear en la lglesia el espacio para un nuevo género literario cristiano que no problematiza ia relación entre la memoria crisliana y la simple sucesión apostólica como su. cesión de obispos en las iglesias loca. les. Hay una evidente preocupación de parte de Eusebio por establecer para cada una de las iglesias locales listas de obispos, los cuales se remontan hasta la edad apostölica. Así, para Jerusalén menciona 15 sucesiones de obispos, número considerado excesivo por Daniélou; ${ }^{7}$ y por lo que toca a Roma describe un minucioso cuadro jerárquico (Hist. Eel., 6,43,44) Otro aspecto de una historia compleja - como sabemos por estudios recientes- que Eusebio simplifica es el siguiente. En el inicio del libro 3 Eusebio afirma que después de la caída de Jerusalén la "tierra habitada" (oikumené) fue repartida en zonas de influencia entre los apóstoles: Tomás entre los Partos, Juan en Asia, Pedro en el Ponto y en Roma, Andrés en la Citia. Esta imagen de la evoiución de la Iglesia presupone el modelo de Iglesia local territorial, modelo que no corresponde a la experiencia de las comunidades iniciales.

También es importante notar el programa que se propone Eusebio al comienzo de su obra. "Habiéndome propuesto consignar por escrito las sucesiones de los santos apóstoles juntamente con los tiempos recorri- dos desde nuestro Salvador hasta no. sotros; cuántas y cuán grandes cosas acontecieron en la hisloria de la igle. sia; los que gobernaron $y$ presidieron gloriosamente la misma Iglesia en las más ilustres sedes: cuántos en cada generación enseñaron la palabra de Dios por palabra o por escrito; cuán. los y en qué tiempos, llevados por ios deseos je nuvedides, cayeron el, errores exiremos, se. prociamaron a si mismos introductores de una falsa ciencia $y$, a modo de lobos voraces, devastaron sin piedad el rebaño de Cristo; cuántas calamidades sobrevinieron inmediatamente, en castigo por su crimeri contra nuestro Salvador, a toda la nación de los judios; de qué modo y en qué tiempo fue la pa. labra divina combatida por los paganos y cuántos por su causa, en diver. sas épocas, pasaron por el combate de sangre y torturas; $y$, además de eso, los martirios que se han dado en nuestra época y cómo se ha mostrado propicia y benigna la ayuda de nuestro Salvador. No voy a comenzar por otro punto, sino por la encarnación de nuestro Salvador y Señor Jesús, el Cristo de Dios" (Hist. Ecl., $1,1)^{9}$ Este programa ignora completamente lo que debe ser una historia de la Iglesia al servicio de la memoria del pueblo cristiano, pues no sigue la linea de la historia de Israel, substituyéndola por la tradición de la his. toriografía dinástica. La tradición de la ley, de los profetas, de la liberación de los humildes y marginados es abandonada en beneficio de la tradición de los instrumentos propios de rememoración de una Iglesia imperia!, que ve en el emperador el tipo de Moisés y David, un hombre escogido por Dios para preparar el camino de Dios y liberar a su pueblo. Los enemigos, para Eusebio, son los montanis- 
tas, los donatistas, los novacianos, o los judios y 'paganos; no son las estructuras del imperio, el poderio de los ricos que explotan a los campesinos con pesados tributos y a los esclavos urbanos. La lgiesia es identificada prácticamente con un grupo dentro de ella: el grupo de los organi. zadores. Nada se dice acerca de los "organizados," a no ser en los relatos de martirios. El programa de Eusebio sive ciertamente como disciplina ecle. siástica a los que tendrán que organı. zar la estructura de la lglesia, pero no sirve como ejercicio eclesial de enraizamiento, rememoración de la alianza de Dios con nosotros que pasa por Abraham, Moisés, los profetas, Jesús, los apostóles, los santos. La me. moria de las luchas y esperanzas del pueblo cristiano que busca resolver urgentes problemas de sobrevivencia, salud, derechos humanos básicos, no encuentra espacio en las páginas de la Historla eclesiástica de Eusebio de Cesarea, ni se repiten en ellas, cosa que es posible, en cada instante y en cada lugar, cambiar el rumbo de las cosas, orientar la vida hacia el éxodo, salir del Egipto del faraón y entrar en la "tierra santa," romper la triste secuencia de dominaciones y humillaciones en la historia de la humanidad.

El éxito del programa de Eusebio de Cesarea en la larga tradición de la historia de la Iglesia como disciplina eclesiástica no debe ser buscado en la originalidad o profundidad de su pensamiento -pues es fácil cuestionar su teologia imperial a partir de los más elementales conceptos de una teología biblica-, sino simple. mente en el hecho de que confirmó por escrito y en forma de tesis el camino que un importante sector de los guias de la Iglesia -que más tarde llegaría a ser hegemónico- comenza. ba ya a trillar, el camino de la alianza entre el estado eclesiástico y la sociedad política del imperio romano. El nuevo modelo de Iglesia, basado en esta alianza, encontró en la "historia de Eusebio una confirmación teórica de su práctica. La teoría virio a confir mar a posteriori una práctica y a cre. ar en torno a ella un consenso eclesial duradero.

Podemos definir el problema de fondo de la siguiente manera. Hay un modo de enfocar la historia de la lglesia que uusca especificamente la pre. servación de la memoria de las institu. ciones que el cristianismo generó a to largo de su experiencia histórica; mientras que otro modo busca la memoria de las múltiples prácticas cristianas en la línea del profetismo.10 Ambos aparecen dialécticamente en la realidad memorial del cristianismo histórico: por un lado, la tradición eusebiana, por el otro, la "profética." La tradición eusebiana sólo puede ser triunfalista o apologética. Triunfalista cuando la institución prospera; apologética cuando se siente amenazada. Ya entre los siglos IV y VI Eusebio fue seguido por autores como Sócrates de Constantinopla, Sezómeno de Constantinopla, Teodoreto de Ciro, Evagrio el Escolástico, Epifanio de Sa. lamina e Isidoro de Sevilla. En la edad media no se estudiaba propiamente la "historia de la Iglesia," pues el interés estaba volcado en la historia de los pueblos cristianizados, los obispa. dos, los monasterios, sus "crónicas" $y$ "memorias," los santos y sus "vidas." Por esto se hace dificil percibir en la edad media los trazos de una tradición eusebiana. Pero con el resurgimiento del interés historiográfico propiamente dicho en la edad moderna 
resucitó también la tradición euse. biana en su vertiente apologética. Al final del siglo XVI, César Baronio (1607) respondiō a los estudios históricos protestantes, los cuales intentaban probar que el protestantismo, $y$ no el catolicismo, era el continuador del cristianismo primitivo, con la publicación de 12 tomos bajo el título Memorias ecleslásticas, obra apolo. gética por excelencia. Hasta el siglo XIX el "Baronio" ejerció influencia predominante en la historia eclesiästica en cuianto disciplina en los semina. rios donde se formaba el clero, inspirando otras obras de dimensiones igualmente gigantescas como la de Rohrbacher, elaborada entre 1842 y 1849 en 29 tomos; la de Hergenröther, entre 1911 y 1917 en 4 tomos, asi como la de Fliche-Martin iniciada en 1936 y proyectada para 24 tomos.

Después del Concilio Vaticano II fueron publicadas dos obras generales de historia de la Iglesia que pretenden ir más allá de la controversia entre católicos y protestantes: el Manual de historla de la Iglesia, en 8 tomos, elaborado en Alemania bajo la dirección de Hubert Jedin (19001980) y la Nueva historia de la Iglesia, en 5 tomos, redactada bajo la dirección de los profesores Rogier (Holanda), Aubert (Bélgica) y Knowles (Inglaterra). En el "Manual" dirigido por Jedin se critica la autoconciencia de la Iglesia como "sociedad perfec. ta" y abre asi espacios saludables para el examen cientifico de la institución, combatiendo la idea un progreso continuo en la historia de la Iglesia y admitiendo períodos de decadencia en el decurrir de esta historia; to. do en la mejor tradición del Concilio Vaticano II. ${ }^{11}$ La Iglesia, segün Jedin, es la reformata reformanda (en continuo proceso de reforma), la eccle- sia semper reformanda. Pero, por otra parte, esa lectura de la historia de la Iglesia desde el lema de la reforma no articula con la necesaria claridad la relación entre reforma de la institución (la famosa reformatio in caplte, la reforma en la cúpula) y reforma en el sentido de movimientos de base (herejias, por ejemplo). ¿Qué formas históricas estän en el origen de los movimientos de reforma? ¿Cuáles son los lugares sociales que condicionan tanto la decadencia como la reforma y qué relación tienen con la sociedad global? El "Manual" no responde a este tipo de preguntas.

En cuanto a la Nueva historia de la Iglesia, el periodo por nosotros estudiado en este ensayo es tratado por el profesor Jean Daniélou, especialista en asuntos relacionados con los primeros siglos cristianos. Leyendo entre líneas el trabajo de Daniélou, se percibe que no tiene mucha simpatia por lo que llama "cristianismo escatológico" o "idealista"12 que se manifiesta en el montanismo o en figuras como Tertuliano, Hipólito y Origenes. ${ }^{13}$ A este cristianismo "idealista," Daniélou opone el modelo llamado "realista" de alianza con los poderes políticos de la época o por lo menos de relativa "paz" con ellos. Daniélou muestra más simpatia por figuras como la de Clemente de Alejandría, quien se movía con facilidad en los medios de la burguesía de Alejandría y dejaba las puertas abiertas para que los ricos entrasen en la Iglesia sin mayores problemas de conciencia. Este gran debate eclesiológico del siglo lll queda resumido por él en las siguientes palabras: "el conflicto de los intelectuales apasionados por una Iglesia ideal con los pastores conscientes de las condiciones de la Iglesia real." 14 La Iglesia que Daniélou 
califica de "ideal" o idealista no es otra que la Iglesia profética, compro. metida con el mensaje de liberación y por esto mismo en conflicto con los poderes de este mundo.

Concluyendo estas breves refle. xiones sobre la ideología que guía el pensamiento tanto de Jedin como de Daniélou podemos decır que ambos. de alguna forma, están en continuidad en un sentido muy amplio con lo que se podría llamar la "tradición eusebiana," pues ambos aceptan, sin dis. cutirlo, un modelo de iglesia que se impuso en el sigla IV y que estaba en discontinuidad con el inodelo de la Iglesia primitiva.

\section{Un nuevo intento historiográfico}

No se puede negar el aporte de Eusebio para el estudio de la historia de la Iglesia. Sin embargo, para elaborar esa historia a partir del pueblo pobre, tres puntos fundamentales deben ser discutidos.

El primero se refiere al encuentro histórico entre el cristianismo y el helenismo, del cual Eusebio habría sido uno de los intérpretes privilegiados. Muchos atribuyen a este encuentro un significado importante: el helenismo habría dado al cristianismo el carácter racional, equilibrado, humanista que éste tiene actualmente y esta habria sido una conquista definitiva. Sin discutir los valores del helenismo hay que recordar, sin embargo, cómo se dio ese encuentro. Se cré la imagen de que este encuentro fue intelectual, teórico, casi planeado. Ahora bien, antes de ser planeado, el encuentro entre el evangelio y el helenismo fue una experiencia vivida durante siglos en la base del edificio cristiano, en las comunidades. Los teólogos que hele- nizaron el cristianismo no fueron más que la expresión sistematizada de al. go vivido en la práctica diaria de los cristianos y que causaba un sinnūmero de problemas. ¿Cómo conservar la pureza de la fe arice las mitologias griegas? ¿Cómo distinguir entre mi. lagro cristiano y magia? ¿Cómo decir que el cristıanismo es una "filosofia"? Los grándes arquitectos de la helenización del cristianismo, quienes recibieron con razón el título de "padres de la Iglesia," respondieron a esas preguntas, pero dieron a su lectura del evangelio dimensiones hegemónicas, casi absolutas, al menos desde la tradiciōn que se creó más tarde. Pero el cristianismo - en el decurrir de su historia - se ha encontrado con problemas provenientes de situaciones muy diversas y distintas a la de la helenización. Asi, el cristianismo se confronta -ya desde hace más de 400 años- con los animismos de América, de Africa y de Asia. Este encuentro es vivido en el día a día de la pastoral cristiana y crea numerosos problemas. ¿Cómo ser cristiano en una cultura africana o de origen africano, en Brasil por ejemplo? Toda la "cuestión de los ritos" en China se resume en las dificultades prácticas de este nuevo encuentro histórico. Ahora bien, los intelectuales cristianos y los teólogos le prestan poca atención a esto y los diccionarios de teología cristiana prácticamente no se ocupan de este asunto en sus gruesos volúmenes, ${ }^{15}$ mientras la teología sistemá. tica casi nada tiene que decir sobre él. Lo único que se necesita en este campo es un espacio para poder reflexionar fuera de los cuadros rigidos que la tradición eusebiana im. pone a la historia de la Iglesia, para que ésta pueda proporcionar a los teólogo los elementos de revisión de 
la relación entre cristianismo y reli. giones populares.

Un segundo punto de divergen. cia con la tradición eusebiana se re. fiere a la erudición. El carácter monu. mental dado a la historia de la Iglesia impresiona, pero al mismo tiempo retrae al lector no iniciado. Frecuente. mente, el historiador puede esconder su falta de metodología so capa de erudición, apabullando con un impresionante cúmulo de hechos, concatenación de rechas, enumeración de acontecimientos, creando la ilusión de la objetividad y olvidando asi -o haciendo olvidar- que son sus propias categorias las que estän actuando al analizar los datos del pasado. El mayor defecto del método de Eusebio de Cesarea está en el haber partido del presupuesto de que la historia evoca pura y simplemente el pasado, y ese defecto pasó de ge. neración en generación por la aplicación al pasado de la experiencia del hoy. Cuando, por ejemplo, hoy discu. timos si la iglesia primitiva era episcopal o no, si era jerárquica o no, si ya exitia desde el principio el primado del papa de Roma, si Jesús 'instituyó' los siete sacramentos, estamos manipulando documentos antiguos con nuestra visión y realidad de hoy, ha cemos decir a los documentos 'muer. tos' - pues toda historiografía se mueve entre los 'muertos' - lo que éstos nunca dijeron, intentamos resu. citar experiencias que no correspon. den a nuestra experiencia de hoy; y esto sucede porque queremos comprobar lo que es hoy nuestra expe. riencia y así, miramos el pasado con esta voluntad de comprobación. Alimentamos entonces la ilusión de que estamos completamente abiertos ante el dato del pasado, que nos dedicamos a la investigación cientifica, pero en realidad estamos sabiendo 'dema. siado,' es decir, no somos conscien. tes del influjo social sobre nuestra me. morla, o por lo menos no suficiente. merite conscientes. En un estudio ya antiguo, pero fundamental, Maurice Halbwache trató de este influjo de la sociedad sobre nuestro modo de lieer el pasado. ${ }^{16}$ Las palabras de Ana:ole France son más sabias: "para sen. tir el espiritu de una época que ya no existe... la dificultad no está tanto en lo que es preciso saber, sino en lo que es preciso no saber más." 17

Frente a la imposibilidad de recuperar el pasado cristiano "como sucedió realmente" (Wie es eigentlich gewesen ist, segün las célebres palabras de Leopold von Ranke, padre del historicismo), es importante realizar al menos algunas tareas modestas: presentar los temas que nos parecen corresponder a los problemas que surgen en el caminar de las comunidades de hoy. Existe un interés social - no sólo individual- en recordar ciertos aspectos y temas relacionados con la Iglesia antigua, pues estos te. mas mantienen la esperanza de hoy. Es importante estar ligados a la gran tradición de esperanza que recorre toda la historia de la Iglesia y defen. der firmemente la memoria cristiana ante el peligro siempre presente de manipulación de esta memoria.

Lo que se quiere decir con esto está admirablemente resumido en las palabras concisas del filósofo Walter Benjamin en una de sus "tesis sobre la filosofía de la historia:" "articular his. tóricamente el pasado no significa conocerlo 'como fue realmente.' Significa conquistar una memoria que resplandece en el momento de un peligro... La tradición debe procurar salvarse en cada época del peligro del 
conformismo, que está a punto de subyugarla. El mesias no viene solamente como salvador, viene también como vencedor del anti-Cristo. El don de suscitar la chispa de esperanza compete solamente a aquella historiografía que está compenetrada de lo siguiente: tampoco los muertos estarăn libres del enemigo, en caso de que éste venza. Y éste enemigo no ha parado de vencer."

Un tercero y ültimo punto se re. fiere a la cuestión del poder. Creemos que es imposible estudiar la historia de la Iglesia sin tocar la cuestión del poder y hacer la pregunta de Leonardo Boff: "la Iglesia institución, zha pasado la prueba del poder?"'i⿱ Cree. mos con el filosófo cristiano Reinhold Schneider que el poder no es propiedad de nadie, sino préstamo de Dios: "usar del poder significa una particular alianza misteriosa con Dios, significa estar a disposiciōn de la gracia." 19 No creemos que Eusebio de Cesarea hizo una lectura propiamente 'cristiana' de las relaciones de poder cuando vio en el imperio romano un modelo incluso para la organizaciōn de la Iglesia y en el emperador el realizador del plan divino, comparable a Moisés o David. No creemos que el emperador pueda ocupar el lugar de una especie de superobispos que coordina los trabajos internos de la Iglesia. Hay que recordar más bien las penetrantes palabras del historiador inglés Lord Acton: "todo poder corrompe $y$ el poder absoluto corrompe absolutamente," y mantener su ley en la investigación de la historia de la Iglesia. Creemos en la posibilidad de la "redefiniciōn de la figura de obispo en un ambiente popular pobre y religioso" 20 según las pa. labras del cardenal Aloisio Lorscheider, asi como la de otros cargos en la Iglesia, a través de la experiencia comunitaria. El poder compartido, al servicio de los humildes, ejercido en la comunidad, no nos parece una fantasīa fuera de la historia.

\section{NOTAS}

1. Altaner-Stuiber, Patrologlo, Barcelona: Herder, 1978, 217.224; M. Greschot, Alte Kirche, 1, Kohihammer, 1984, 294.235.

2 J Daniélou. Nova Históría de Igreje, 1 Brasil: Vozes. 1966, 33.

3 J. Daniëlou, Ibidem, 52.

4. Ibldem, 118

5. Ibldem, 123.

6. Altaner-Stuiber, 185-188.

7. Daniêlou, 70

8. Ibidem, 206.

9. $H$. Jedin, Manual de historia de la Iglesia, 1, Barcelona: Herder, 1966, 52.

10. Estudios biblicos, 4, Brasil: Vozes, 1984, passim.

11. G. Alberigo, '.'Relorme' en tant que critére de I'histoire de I' Eglise" Revue d'His. toire Eccléslastlque, Lovaina, 198176 , 72-81.

12. J. Daniélou, 155.

13. Ibidem, 120 e 155.

14. Ibidem, 155.

15. El famoso Dictionnalre de Theologie cathollque, de más de 30 volúmenes, trata del animismo en tres columnas (15, 3099 y 0. 559 ss.) para condenar los desvios de un pensador europeo; el diccionario alemán Dle Religlonen in Geschichte und Gegenwart, en 6 volúmenes, dedica 3 columnas al animismo (1. 389-391) comentando las doctrinas del antropólogo E.8. Tyior (1871); el Lexikon Pür Theologie und KIrche, de 10 volúme. nes, dedica una columna al animismo (1,565-566) para hablar del mismo Tylor; el Diccionario de teología de Fries, editado en Brasıl en 5 volúmenes, $n$ siquiera menciond $e$ asunto.

16. M. Halbwachs. Les cadres sociaux de la mémoire, Paris, 1925.

17. Citado por Ecléa Bosi, Memória e sociedade, SSo Paulo: 1979, 21.

18. L. BOH, Igreja, carlsma e pooer, Brasil: Vozes, 1981, 85.

19. En la Reviste Humboldt, 1963, 7, 99-102.

90. Aloisio Lorscheider, "A Redefinıçāo da figura do bispo no meio popular pobre e religioso," Conclllum, 1984, 754757 (ed. brasileira). 